\title{
Differences in phasic development rate amongst wheat cultivars independent of responses to photoperiod and vernalization. A viewpoint of the intrinsic earliness hypothesis
}

\author{
G. A. SLAFER* \\ Centre for Crop Improvement, Department of Agriculture, The University of Melbourne, Parkville, \\ Victoria 3052, Australia
}

(Revised MS received 12 June 1995)

\begin{abstract}
SUMMARY
Differences amongst wheat cultivars in the rate of reproductive development are largely dependent on differences in their sensitivity to photoperiod and vernalization. However, when these responses are accounted for, by growing vernalized seedlings under long photoperiods, cultivars can still differ markedly in time to ear emergence. Control of rate of development by this 'third factor' has been poorly understood and is variously referred to as intrinsic earliness, earliness in the narrow sense, basic vegetative period, earliness per se, and basic development rate. Certain assumptions are made in the concept of intrinsic earliness. They are that differences in intrinsic earliness (i) are independent of the responses of the cultivars to photoperiod and vernalization, (ii) apply only to the length of the vegetative period up to floral initiation (as suggested by several authors), (iii) are maintained under different temperatures, measured either in days or degree days. As a consequence of this, the ranking of cultivars (from intrinsically early to intrinsically late) must be maintained at different temperatures. This paper, by the re-analysis of published data, examines the extent to which these assumptions can be supported.

Although it is shown that intrinsic earliness operates independently of photoperiod and vernalization responses, the other assumptions were not supported. The differences amongst genotypes in time to ear emergence, grown under above-optimum vernalization and photoperiod (that is when the response to these factors is saturated), were not exclusively due to parallel differences in the length of the vegetative phase, and the length of the reproductive phase was independent of that of the vegetative phase. Thus, it would be possible to change the relative allocation of time to vegetative and reproductive periods with no change in the full period to ear emergence.

The differences in intrinsic earliness between cultivars were modified by the temperature regime under which they were grown, i.e. the difference between cultivars (both considering the full phase to ear emergence or some sub-phases) was not a constant amount of time or thermal time at different temperatures. In addition, in some instances genotypes changed their ranking for 'intrinsic earliness' depending on the temperature regime. This was interpreted to mean that while all genotypes are sensitive to temperature they differ amongst themselves in the extent of that sensitivity.

Therefore, 'intrinsic earliness' should not be considered as a static genotypic characteristic, but the result of the interaction between the genotype and temperature. Intrinsic earliness is therefore likely to be related to temperature sensitivity. Some implications of these conclusions for plant breeding and crop simulation modelling are discussed.
\end{abstract}

\footnotetext{
* Present address: Departamento de Produccion Vegetal, Facultad de Agronomia, Universidad de Buenos Aires, Av. San Martin 4453, 1417 Buenos Aires, Argentina.
} 


\section{INTRODUCTION}

An understanding of the factors underlying genotypic variation in pattern of development is critical for plant breeding and crop simulation modelling. Breeders can take advantage of this knowledge by using different factors to customize crops to fit within the variable growing season as well as to allocate different proportions of time to vegetative or reproductive growth as a potential avenue for manipulating source-sink relationships. Modellers have to use genetic coefficients to differentiate between cultivars in their simulations of growth and development. There has been considerable research to identify what factors determine the lengths of different phases of development and what genetic variation in response to these factors is available (see review by Slafer \& Rawson 1994).

The fact that environmental factors do affect the developmental patterns of a crop is demonstrated when sowing date is changed (Angus et al. 1981 a; Kirby et al. 1985, 1987; Hay 1986; Savin 1993), or when crops are grown at different locations and compared (e.g. Bauer et al. 1988). Then, changes in the time to different phenological stages may occur, and it can be seen that the magnitude of these changes is cultivar-dependent.

The main environmental factors affecting phasic development in wheat are photoperiod, vernalization and temperature (Pirasteh \& Welsh 1980; Fischer 1984; Hay \& Kirby 1991; Slafer \& Rawson 1994). Photoperiod and vernalization are usually considered to account for almost all if not all of the differences between cultivars in development rate. These responses have been studied in detail and there are many papers reporting the responses of wheat to photoperiod and vernalization (e.g. Halloran 1977; Rahman \& Wilson 1977; Major 1980; Davidson et al. 1985; Flood \& Halloran 1986; Manupeerapan et al. 1992; Slafer et al. 1994). A general model for the effects of both factors on the duration of the period to ear emergence or anthesis (Fig. 1a) or on its reciprocal, the rate of development towards ear emergence or anthesis (Fig. $1 b$ ), includes two ranges of these factors dividing the response into two types of reaction, one responsive (for the below-optimum values of photoperiod and vernalization) and one unresponsive (for the above-optimum values of photoperiod and vernalization). For the first range of values, the longer the daylength under which the plants are growing, or the longer the vernalization pretreatment, the shorter the time taken to ear emergence or anthesis (Fig. la), or the faster the rate of development (Fig $1 b$ ). At some daylength or vernalization pretreatment (optimum photoperiod or optimum vernalization) the maximum response is reached (i.e. the minimum time or the fastest rate of development). These optimum photoperiod and vernalization values, as well as the
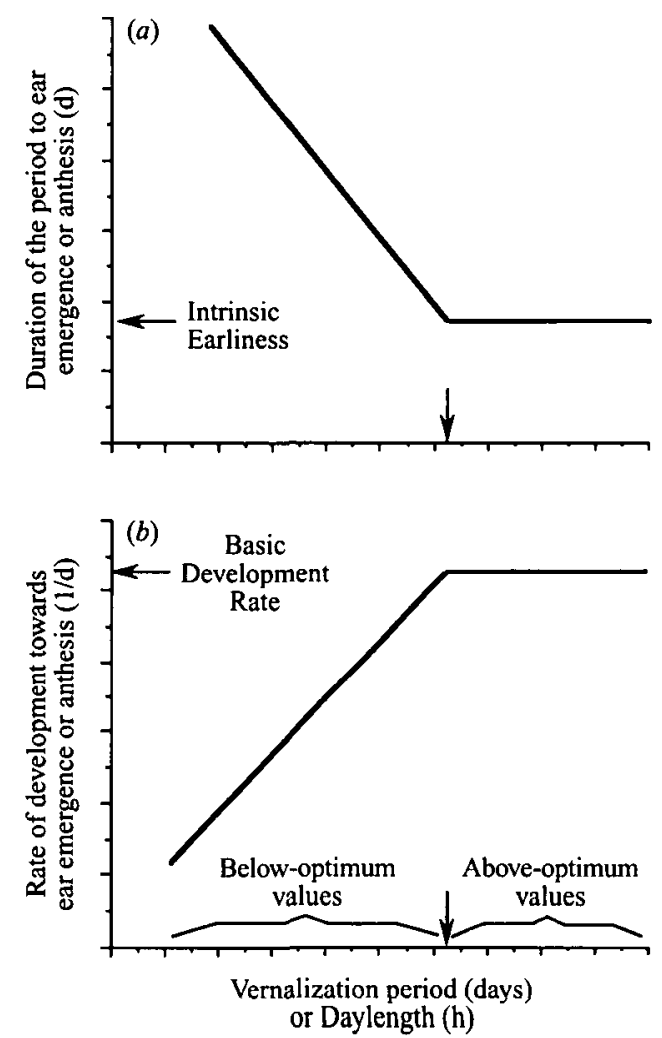

Figure 1. A schematic diagram of the changes in (a) duration and $(b)$ rate of development for the period to ear emergence or anthesis under different photoperiods and vernalization treatments. The horizontal arrows indicate the minimum time or 'intrinsic earliness' $(a)$ and the fastest rate or 'basic development rate' $(b)$ under above-optimum values of photoperiod and vernalization. The vertical arrows in both diagrams indicate the values of optimum photoperiod and vernalization.

magnitude of the slope for the response to belowoptimum levels of photoperiod and vernalization are specific for each cultivar. The differences amongst cultivars in these two parameters are then responsible for most of the differences in their time to anthesis under field conditions.

However, it has been suggested that there might be an important 'third factor', additional to photoperiod and vernalization, which might affect phasic development. Syme (1968) found that two cultivars which had the same responses to photoperiod and vernalization did not reach ear emergence at the same time. Others confirmed this by showing that cultivars could differ in their rate of development even when their requirements for vernalization and photoperiod were fully satisfied by growing them under aboveoptimum photoperiod and vernalization conditions (Aitken 1974; Halloran 1977; Major 1980; Ford et al. 1981; Flood \& Halloran 1984; Hoogendoorn 1985). 
This means that cultivars can also differ in the values of minimum duration to or maximum rate of development towards anthesis (those corresponding to above-optimum photoperiod and vernalization; Fig. 1).

In passing, it should be noted that the term optimum is used here to refer to the values of photoperiod and vernalization under which the response to these factors is saturated (Fig. 1), i.e. the period to reach a particular stage of development is minimum. It does not mean that under these conditions the time to anthesis is optimum for subsequent yield, which might or might not be the case depending on the particular location and cultivar under analysis.

Because these differences amongst genotypes are evident when the requirements for photoperiod and vernalization are fully satisfied, and since it is supposed that cultivars do not differ in their response to temperature (see Takahashi \& Yasuda 1971), these differences should be 'intrinsic'. In other words, the value of the 'third factor' should be immutable for a cultivar. Although this hypothetical factor has been called several names (see Table 1), 'intrinsic earliness' (Masle et al. 1989) and 'basic development rate' (Flood \& Halloran 1984) are used in the present paper for referring to this 'third factor' in terms of duration and rate of development, respectively.

In this paper, an attempt is made to reach a greater understanding of intrinsic earliness by (i) reviewing the literature in which the concept was considered; (ii) enumerating the implicit assumptions underlying the concept; and (iii) re-analysing results from several studies to determine to what extent the concept and its assumptions hold across a diversity of thermal conditions.

\section{DETERMINATION OF INTRINSIC EARLINESS AND A GENERAL DESCRIPTION OF THE CONCEPT}

Davidson et al. (1985) grew 24 varieties of wheat in a glasshouse experiment at $20^{\circ} \mathrm{C}$, to compare the effects on development of the factorial combination of five vernalization periods and two photoperiods. In Fig. 2 it is shown that most of their differences in time to ear emergence, which ranged from 40 to $>250$ days (Fig. $2 a$ ), were due to the differential sensitivities of the cultivars to vernalization and photoperiod, because when plants were grown under a long photoperiod following the imposition of a long period of vernalization the range between cultivars was then markedly reduced (40-70 days; Fig $2 b$ ). Thus, after removing the responses to photoperiod and vernalization their cultivars still differed in the time taken to ear emergence by up to 30 days. Consequently, the difference of up to 30 days in the time taken to ear emergence may be attributed to their intrinsic earliness.
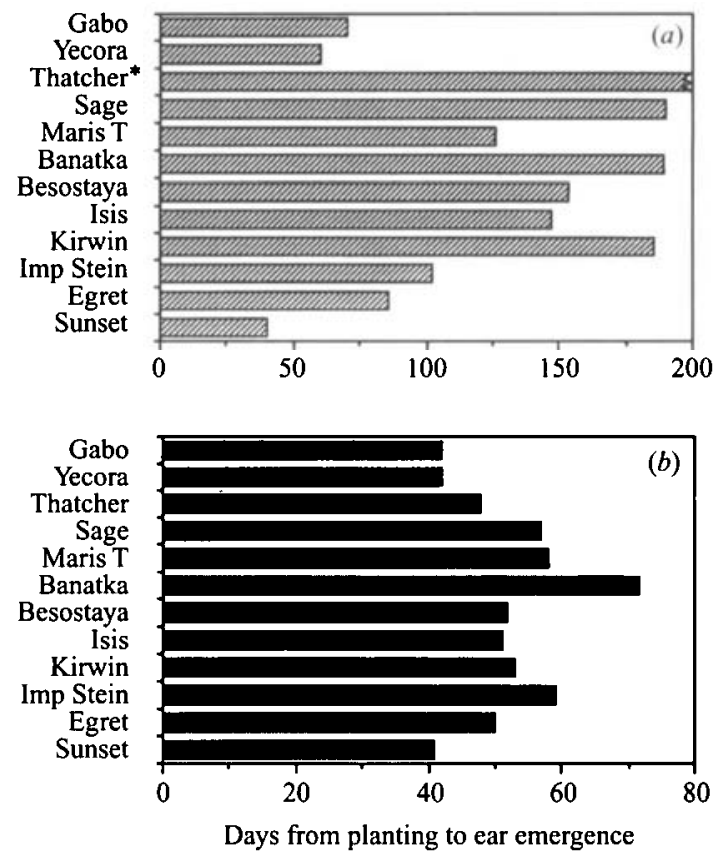

Figure 2. Time from planting to ear emergence of different cultivars grown under $(a)$ short photoperiod $(<11 \mathrm{~h})$ after no vernalization; and $(b)$ under long photoperiod $(16 \mathrm{~h})$ and after 56 days of vernalization. Cultivars were selected from Fig. 3 in Davidson et al. (1985). Maris T is the cultivar Maris Templar and the asterisk means that Thatcher under short photoperiod did not reach ear emergence within the 250 days of the experiment.

Table 1 summarizes previous work with wheat in which intrinsic earliness was identified and explicitly discussed. A similar trait has also been discussed for other crops, such as barley (Takahashi \& Yasuda 1971; Yasuda 1981; Boyd et al. 1991; Young \& Elliott 1994), rice (Vergara \& Chang 1976), maize (Beavis et al. 1991; Koester et al. 1993) and other crops (Major 1980). In most of the wheat studies, the trait has been classified as a major factor affecting development, or at least as a minor, residual factor (Keim et al. 1973). Although the effect of the trait was usually measured as time to ear emergence, there was often a suggestion that this genetic factor would only affect the length of the vegetative phase (Aitken 1974; Major 1980; 1983; Wallace 1985; Masle et al. 1989; Vongburi 1992; Worland et al. 1994), prior to stem elongation.

All studies in Table 1, with two exceptions, were conducted under a single temperature regime. It is possible that where temperature was not included as a variable it was assumed that all cultivars may have a similar sensitivity to temperature (Takahashi \& Yasuda 1971). This is in agreement with Worland $e t$ al. (1994), who stated that intrinsic earliness genes act independently of environmental stimuli. Thus, ir- 


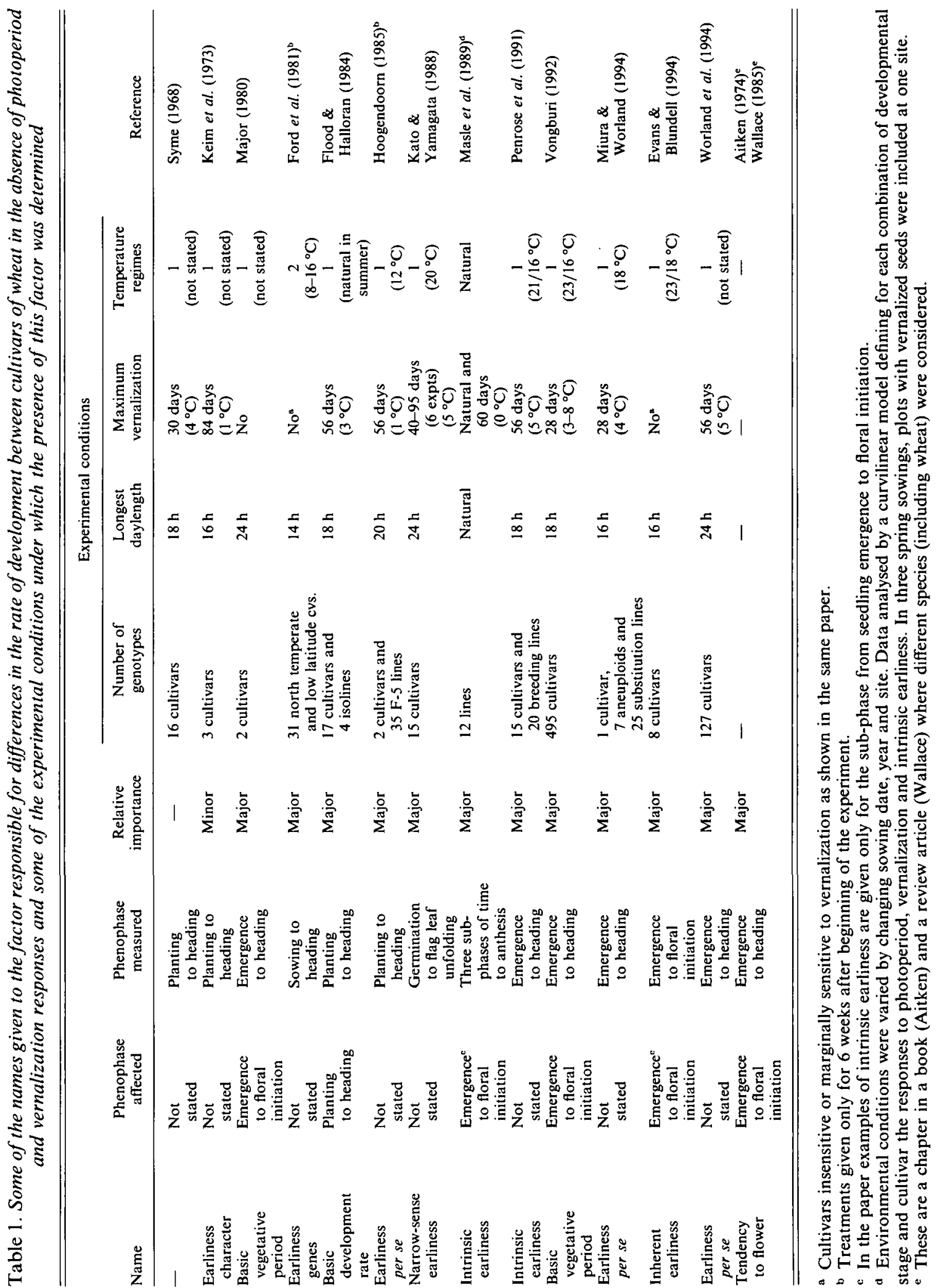


respective of the thermal environment, the differences between cultivars in time to ear emergence (either measured as calendar or thermal time) would remain the same. This assumption could be based on the implicit recognition that plant development has a universal response to temperature (Aitken 1974), i.e. the rate of development of all cultivars and all phenophases are sensitive to temperature (Slafer \& Rawson 1994).

It is difficult to provide an exact definition of intrinsic earliness, but judging from several studies (Table 1), it seems that there is a general consensus that it could be described as:

'a major, intrinsic factor affecting the length of the vegetative phase (i.e. the time to floral initiation) independently of any effects of photoperiod and vernalization. i.e. it is responsible for any difference in time to ear emergence amongst genotypes under above-optimum photoperiod and vernalization conditions, when the responses to photoperiod and vernalization are saturated (Fig. 1)'

This is the definition that is examined in the following discussion. This definition includes three conditions which will be discussed.

\section{Intrinsic earliness is not associated with photoperiod and vernalization response}

If intrinsic earliness exists, it should be possible to produce cultivars which should have a sensitivity independent of photoperiod and vernalization. Thus, the time to (or its reciprocal, the rate of development towards) ear emergence or anthesis under optimal values of both photoperiod and vernalization should be independent of the sensitivity to these factors.

\section{Cultivars only differ for intrinsic earliness in the length of the vegetative period}

This assumption implies that, under above-optimum photoperiod and vernalization conditions, any difference amongst cultivars in time to ear emergence must be due entirely to equivalent differences in the time to floral initiation. This is a speculation that has not been rigorously tested yet, but that has been accepted in several papers on intrinsic earliness (see Table 1). Mathematically the regression coefficient of the relationship between time from seedling emergence to ear emergence and time from seedling emergence to floral initiation for different cultivars under a single temperature has to be 1 . Also, the intercept of that relationship must be positive and equal to the time from floral initiation to heading in all cultivars. Similarly, the regression of the duration of the reproductive phase against that of the vegetative phase must give a slope of 0 and the intercept must indicate the time from floral initiation to heading in all cultivars.

If this assumption in the definition was correct, plant breeders could readily evaluate differences amongst lines in the length of the vegetative period simply by recording their differences in time to ear emergence. But if the length of the vegetative and reproductive sub-phases were independent of each other, the selection process would be much more complex. It would require an estimate of the timing of each stage of development and so would be unlikely to be attempted in conventional breeding programmes. However, this alternative would be one avenue towards independent manipulation of the lengths of different sub-phases (Halloran \& Pennell 1982). Furthermore, different combinations of durations of sub-phases could be used to achieve the same duration to heading.

\section{Differences in intrinsic earliness amongst genotypes are unaffected by temperatures}

There is no doubt that temperature strongly affects plant development (Johnson \& Thornley 1985; Frank et al. 1987; Porter \& Delécolle 1988; Morrison et al. 1989); and linear relationships between the rate of development (the reciprocal of the duration) and mean temperature have frequently been reported (Monteith 1977; Gallagher 1979; Angus et al. $1981 b$; Morrison et al. 1989; Slafer \& Savin 1991; Slafer \& Rawson 1995a), giving support to the use of thermal time to negate the effect of temperature under field conditions.

If there is an absence of effect of temperature on the differences in intrinsic earliness among cultivars; then it follows that difference between cultivars under two thermal regimes can be constant in calendar (days) or thermal (degree days) time.

\section{Differences in calendar time are constant}

If differences between cultivars remain at a constant number of days as temperature varies, it does not necessarily mean that development is insensitive to temperature, because it might also be that intrinsic earliness is equally temperature-sensitive in all cultivars. This situation is represented in Fig. $3 a$ where the duration of the period to ear emergence is compared at two temperatures. In this example, the duration of the period to ear emergence is arbitrarily reduced by $c .27$ days for all cultivars when they are grown at high temperature, independently of the actual duration of this period at low temperature. Therefore, their differences in days at high and at low temperatures are unaltered. This model has a slope of 1 and a negative intercept, and the reduction in time to heading due to high temperature for all cultivars is the intercept on the abscissa (Fig. 3a).

\section{Differences in thermal time are constant}

If the differences between cultivars in time to ear emergence are affected by temperature, the reduction in time due to increased temperature would be directly 

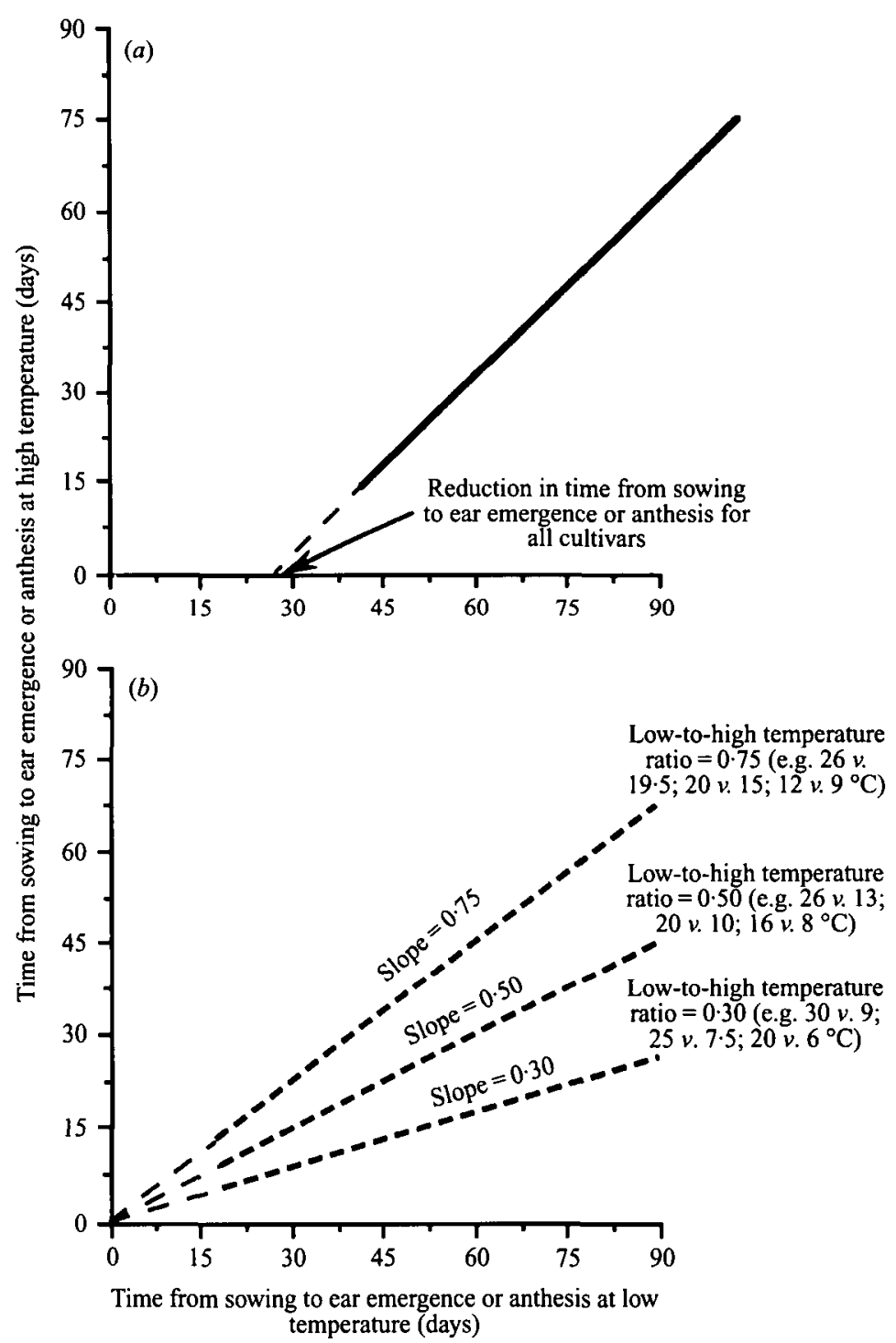

Figure 3. A schematic diagram of the relationship between the duration of the period from sowing to ear emergence or anthesis at high temperature versus that at low temperature at a constant vernalization and photoperiod. The relationships represent the assumption that differences amongst cultivars remain constant in $(a)$ calendar time and $(b)$ thermal time. For Fig. $3 b$, different slopes were drawn to illustrate different combinations of high and low temperature, and in all cases a base temperature of $0{ }^{\circ} \mathrm{C}$ was used.

associated with the length of the period of intrinsic earliness for each cultivar. For example, a cultivar with an intrinsically long period to ear emergence will have a greater reduction in calendar time due to high temperatures than a cultivar with an intrinsically short period. Thus their differences in calendar time will be less under high than under low temperature, but they will be the same in thermal time.

This situation is represented in Fig. $3 b$ where the duration of the period to ear emergence under high temperature is shown versus the same period under low temperature. If the base temperature is $0^{\circ} \mathrm{C}$, then the ratio of low-to-high temperature in the experiment will give a slope for the relationship which has an intercept of 0 . At any point on the corresponding line each cultivar has the same thermal time to ear emergence under low and high temperature. Thus, the difference between cultivars at any temperature is constant in degree days.

In this example it is assumed that all cultivars have a base temperature of $0{ }^{\circ} \mathrm{C}$. If the base temperature is different from $0{ }^{\circ} \mathrm{C}$, the estimate of the slope would be 


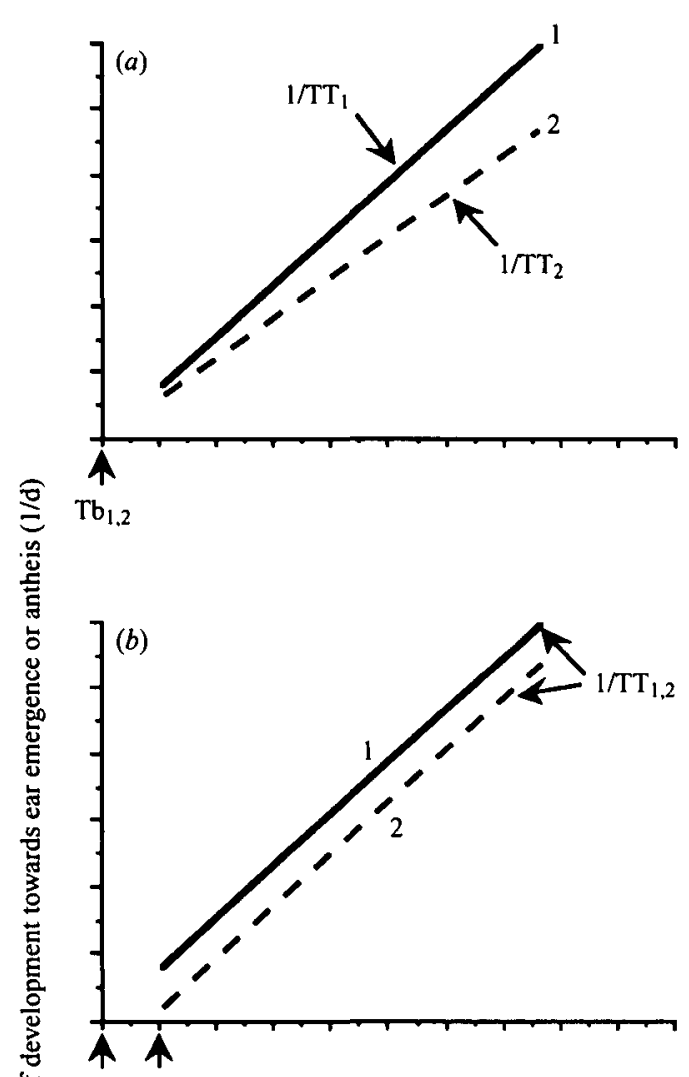

$\begin{array}{ccc}\mathrm{Tb}_{1} & \mathrm{~Tb}_{2}\end{array}$

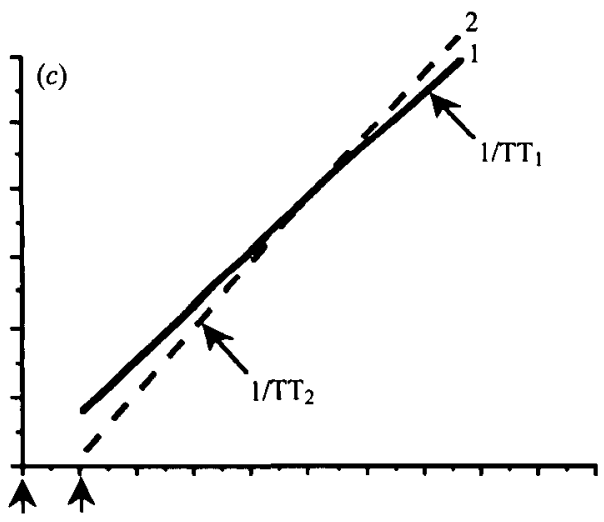

$\begin{array}{lll}\mathrm{Tb}_{1} & \mathrm{~Tb}_{2}\end{array}$

Mean temperature $\left({ }^{\circ} \mathrm{C}\right)$

Figure 4. A schematic diagram of the relationship between the rate of development towards ear emergence or anthesis and temperature. The relationships were constructed to keep differences amongst cultivars constant in $(a)$ thermal time or (b) calendar time. Fig. $4 c$ illustrates one possibility for cultivars with differential sensitivity to temperature in which they change their ranking depending on temperature. 1/TT and $\mathrm{Tb}$ refer to the reciprocal of the slope (that is the thermal time) and the base temperature for cultivars 1 (-) and 2 (----).
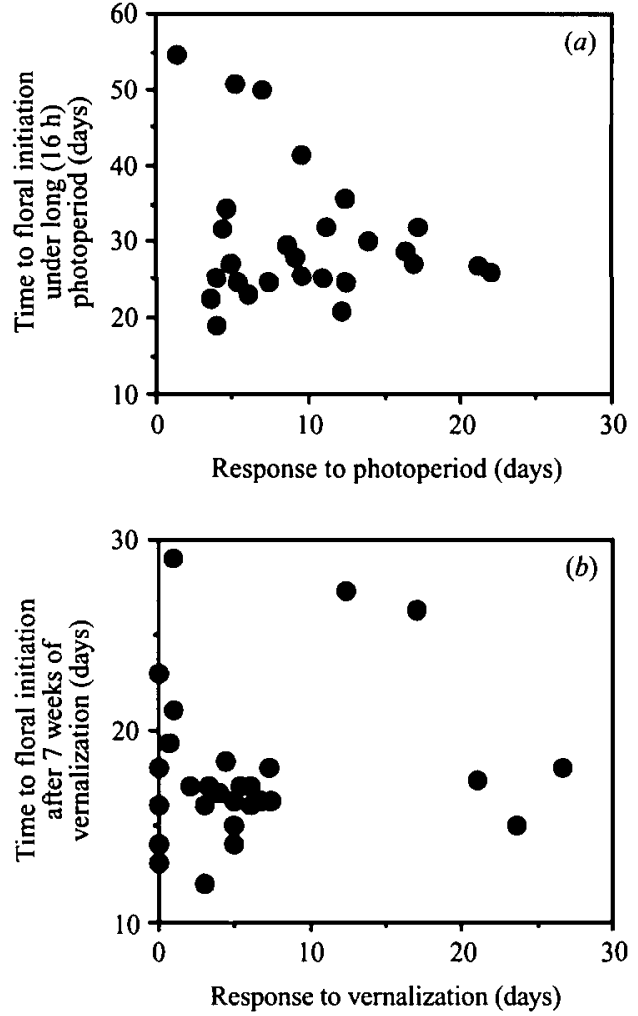

Figure 5. Relationship between the length of the vegetative phase after removing the effects of photoperiod and vernalization and the response of the cultivars to $(a)$ photoperiod $(10 v, 16 \mathrm{~h}$ ) and $(b)$ vernalization (not vernalized $v$. vernalized for 49 days at $4{ }^{\circ} \mathrm{C}$ ). The responses were estimated as the difference in time under short photoperiod or no vernalization, and that under long photoperiod or after 49 days of vernalization $((a)$ and $(b)$ respectively). A few cultivars with a qualitative response (i.e. plants did not reach floral initiation under short photoperiod or in unvernalized seedlings) were not included. Data from Rahman (1980).

given by the ratio between the temperatures used in the experiment after subtracting from them the appropriate base temperature which could be any value but the same for all cultivars: [ $\left(\mathrm{LT}-\mathrm{T}_{\mathrm{b}}\right)$ $\left(\mathrm{HT}-\mathrm{T}_{\mathrm{b}}\right)^{-1}$; where LT and HT stand for low and high temperature respectively and $T_{b}$ is the base temperature for all cultivars]. The intercept must be 0 irrespective of the base temperature used.

\section{Differences amongst cultivars as part of their response to temperature}

The models shown in Fig. 3 are a simplification of the responses of developmental rates to temperature. Simplification is necessary because most of the research conducted involving temperature as a factor (particularly under long photoperiod and after a long 

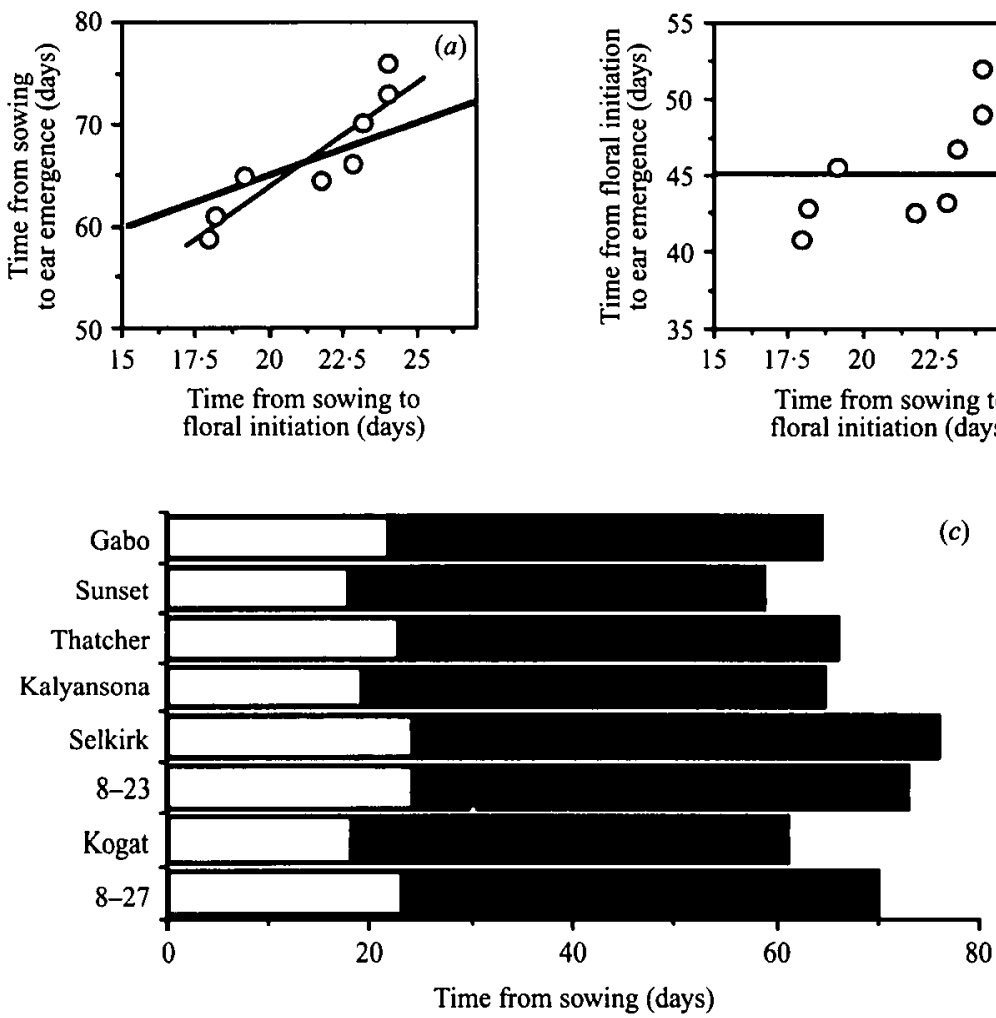

Figure 6. Relationship (a) between the duration of the period from sowing to ear emergence and the duration of the vegetative phase; and $(b)$ between the duration for the reproductive phase and the duration of the vegetative phase, for eight cultivars (insensitive or marginally sensitive to vernalization) when plants were grown under $24 \mathrm{~h}$ photoperiods at $16 / 9^{\circ} \mathrm{C}$ (Rahman \& Wilson 1978). Comparisons of actual durations from sowing to floral initiation ( $\square$ ) and from floral initiation to ear emergence (reproductive phase, $\square$ ) for these cultivars are shown in $(c)$. Heavy lines represent the theoretical models if cultivars differ for intrinsic earliness in the length of the vegetative period, using as intercept the average length of the reproductive phase for all the cultivars (45.3 days) and a slope of 1 or $0((a)$ and $(b)$, respectively). The light line was fitted by regression.

period of vernalization) used only two (or three) temperatures and therefore it would not be possible to assess alternative or more complex explanations. The model supporting the relationships shown in Fig. 3 assumes that the rate of development towards ear emergence is linearly related to temperature, between a base and an optimum temperature (but see Angus $e t$ al. $1981 a$; Slafer \& Rawson 1995a). The models have two major components (i) the intercept on the abscissa, which indicates the base temperature and (ii) the regression coefficient, that is the reciprocal of the thermal time using the base temperature stated in (i).

The hypothesis that differences between cultivars are constant in degree days at any thermal regime is represented in Fig. 4a. In this Figure, cultivars do not differ in base temperature and the difference is the slope (whose reciprocal is the thermal time). In this example, cultivar 1 is intrinsically earlier than cultivar
2 by the same number of degree days at any temperature.

An alternative, which would also fulfil the requirements for the concept of intrinsic earliness, is that cultivars differ in time to ear emergence by a constant calendar time, and the reason for the differences would be differences in their base temperature rather than in their thermal time (Fig. $4 b$ ). However, if cultivars differ simultaneously in both base temperature and thermal time required to reach heading the concept of intrinsic earliness would be seriously challenged, since differences between cultivars would not be constant in either days or degree days. If the cultivar with the lowest base temperature also had the lowest slope (Fig. 4c), and thus the longest thermal time, it would be possible for either cultivar to be later or earlier, depending on the temperature under which the comparison was made. 

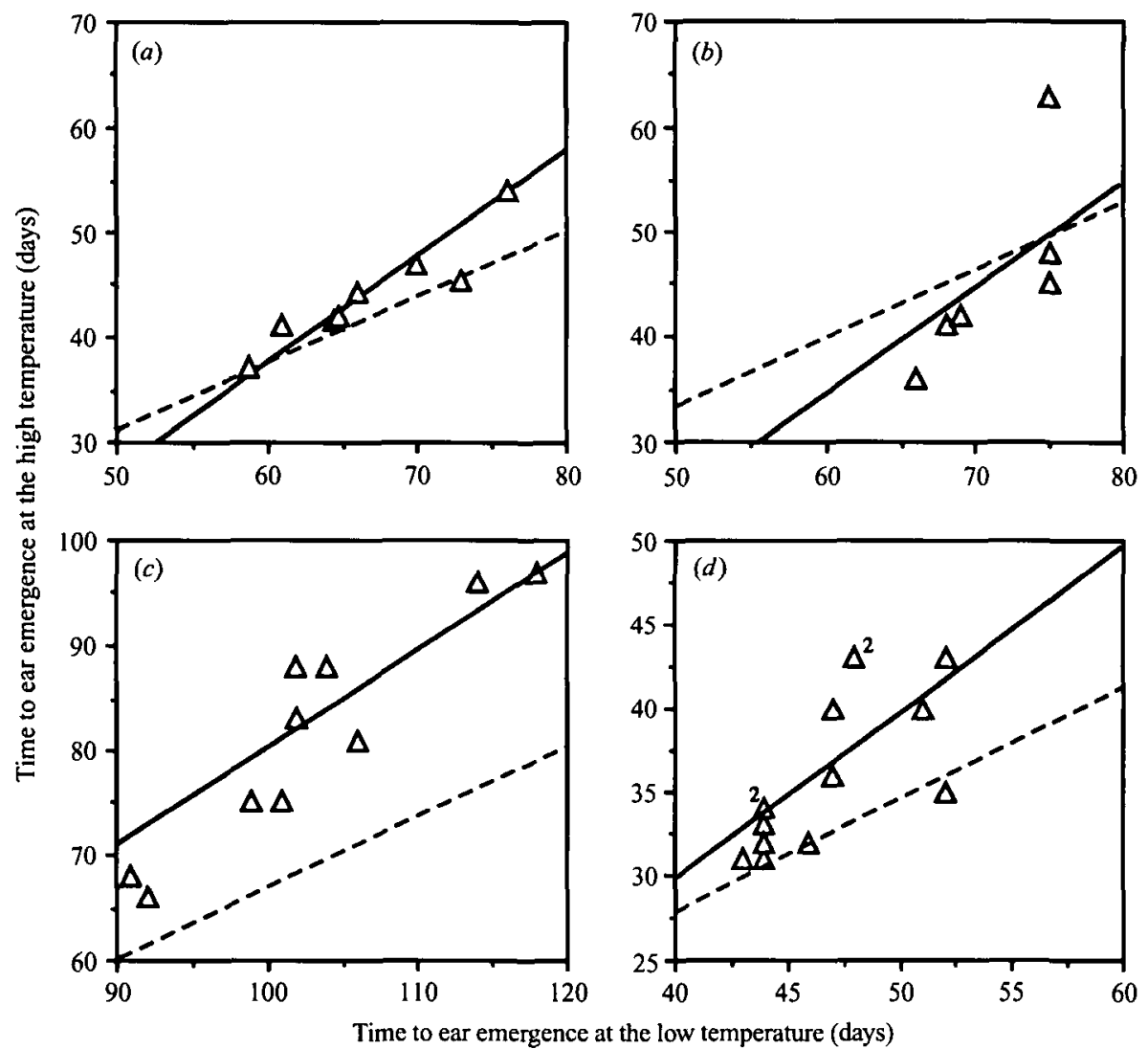

Figure 7. Relationship between the duration for the period to ear emergence at high temperature versus that at low temperature in different studies with several genotypes: $(a) 8$ cultivars largely insensitive to vernalization grown at day/night temperatures of $16 / 9^{\circ} \mathrm{C}$ or $23 / 16^{\circ} \mathrm{C}$ under 24 h photoperiod and no vernalization (Rahman \& Wilson 1978), (b) 6 cultivars largely insensitive to vernalization grown at day/night temperatures of $21 / 16^{\circ} \mathrm{C}$ or $15 / 10^{\circ} \mathrm{C}$ under a daylength of $16 \mathrm{~h}$ and no vernalization (Rawson 1970), (c) 10 cultivars grown at day/night temperatures of $21.0 / 12.7^{\circ} \mathrm{C}$ or $15.5 / 7.2{ }^{\circ} \mathrm{C}$ under increasing daylength from $10-14 \mathrm{~h}$ and 70 days vernalization and no vernalization for the winter and spring cultivars, respectively (Pirasteh \& Welsh 1980), (d) 14 cultivars grown at day/night temperatures of $25 / 20^{\circ} \mathrm{C}$ or $18 / 13^{\circ} \mathrm{C}$ under a daylength of $14 \mathrm{~h}$ and 28 days of vernalization (Wall \& Cartwright 1974). Lines representing the assumption that differences amongst cultivars remain constant in calendar time, using as intercept on the abscissa the average reduction of all cultivars in each study (-), and in thermal time (-.--) (see Fig. 3).

\section{TESTING ASSUMPTIONS}

To test the above assumptions, data from the literature are used. These data were always obtained from experiments comparing different cultivars grown under a long photoperiod and after a long period of vernalization, or comparing photoperiod- and vernalization-insensitive cultivars. These data will be compared with the theoretical models already described.

\section{Intrinsic earliness is not associated with photoperiod and vernalization response}

Rahman (1980) conducted two experiments to de- termine the effects of photoperiod and vernalization on the duration of the vegetative period of several wheat cultivars. The intrinsic earliness of the cultivars, measured as the time taken to floral initiation (estimated as double ridge) under long photoperiod after seeds were vernalized, was not associated with sensitivity of the cultivars to photoperiod $\left(R^{2}=0.05\right.$; Fig. $5 a)$, nor to vernalization $\left(R^{2}=0.01\right.$; Fig. $\left.5 b\right)$.

Davidson et al. (1985) grew 117 genotypes of wheat after 0 and 6 weeks vernalization in combination with 11 and $16 \mathrm{~h}$ photoperiod at an average temperature of $20^{\circ} \mathrm{C}$. It has been shown, after reanalysing their data (Fig. 4 in Slafer \& Rawson (1994)), that differences in intrinsic earliness amongst genotypes were not associated with the magnitude of their responses to photoperiod or vernalization, as the 


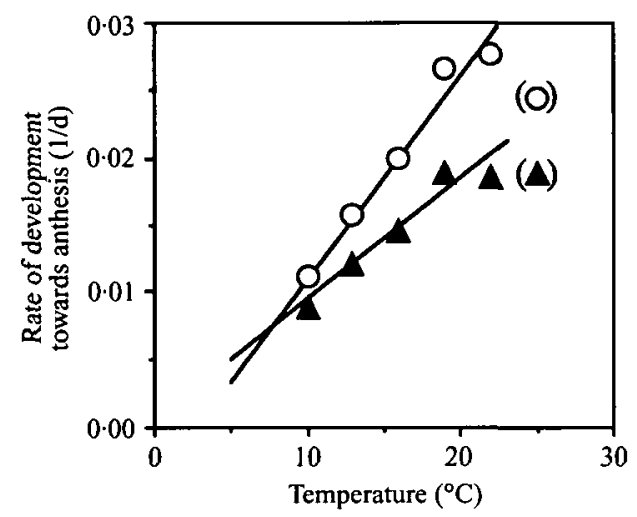

Figure 8. Relationship between the rate of development towards anthesis and temperature for the cultivars Sunset (O) and Cappelle Desprez (A) grown in sunlit cabinets under long photoperiod $(18 \mathrm{~h})$ and after being vernalized for 50 days at six constant temperatures ranging from 10 to $25^{\circ} \mathrm{C}$ (Slafer \& Rawson 1995a). The lines were fitted by linear regression. Data between brackets were not included in the analysis as they were considered to be above the optimum temperature.

range in intrinsic earliness was generally similar at any level of response.

It was clear in both studies that 'genes' for intrinsic earliness could be responsible for differences between cultivars in phasic development in wheat, and that these 'genes' could be present in any combination with those for sensitivity to photoperiod and vernalization. This agrees with the expectation of the authors listed in Table 1, and gives support from independent data to the first assumption.

\section{Cultivars only differ for intrinsic earliness in the length of the vegetative period}

Rahman \& Wilson (1978) measured the duration of three sub-phases of time to ear emergence (from seedling emergence to floral initiation, from floral initiation to terminal spikelet initiation, and from terminal spikelet initiation to ear emergence) of several cultivars which are largely insensitive to vernalization, under continuous light $(24 \mathrm{~h}$ photoperiod) and at $16 / 9^{\circ} \mathrm{C}$. Their data make it possible to assess whether or not differences among cultivars in intrinsic earliness are restricted to the vegetative period, or if differences occur also (independently of any effect of photoperiod or vernalization) in the duration of the reproductive phases.

The length of the full period to ear emergence was positively related to the length of the vegetative period $\left(R^{2}=0.802, P<0.05\right.$; Fig. $\left.6 a\right)$, which is an expected result since the latter is just a sub-phase of the former. However, the slope of the relationship $(2.06 \pm 0.42)$ was significantly $>1$ (Fig. $6 a$ ), which is the expected slope if the differences amongst cultivars in time to ear emergence were exclusively due to differences in the lengths of their vegetative period.

The cultivars not only significantly $(P<0.01)$ differed in the length of the reproductive phase from floral initiation to ear emergence in the absence of photoperiod or vernalization effects, but also the length of the reproductive phase was independent of the length of the vegetative phase $\left(R^{2}=0.518\right.$, $P>0 \cdot 10$; Fig. $6 b$ ). Thus, it should be possible to have combinations of long vegetative with short reproductive phases and vice-versa.

Figure $6 c$ shows the actual values for each of these sub-phases in the eight cultivars used by Rahman \& Wilson (1978), in which combinations of different lengths of vegetative and reproductive phases are clear. For example, comparing Selkirk and 8-27, both cultivars had the same vegetative phase, but Selkirk had a longer reproductive period. Gabo and Sunset showed the opposite, with similar durations of the reproductive phase but differences in the length of the vegetative phase (Fig. 6c).

From these data, it appears that the second assumption in the concept of intrinsic earliness is not correct, and that cultivars, in the absence of photoperiod and vernalization response, can differ not only in the length of the period to floral initiation but also in the length of the reproductive phases.

\section{Differences in intrinsic earliness amongst genotypes are unaffected by temperature}

\section{Differences in time to ear emergence or anthesis}

In the analysis made by Slafer \& Rawson (1994), it was clear that not only were all genotypes responsive to temperature but that there was genotypic variation in sensitivity to temperature when the differences in time to heading of different cultivars within each experiment were compared. Quantitatively, the differences amongst cultivars ranged from 3- to 5-fold and the sensitivity to temperature of each cultivar was independent of the duration of its period to heading (Fig. 7 in Slafer \& Rawson (1994)). They suggested that

'(i) if cultivars differ in the magnitude of their response to temperature and (ii) if there is no association between this sensitivity and the duration of the period to heading, it would be also possible to speculate that the basic development rate is not only a genotypic characteristic but a result of the interaction between the genotype and the thermal environment'.

Rahman \& Wilson (1978) and Rawson (1970) included in their studies wheat cultivars which are insensitive to vernalization under long photoperiod. When the length of the period to ear emergence at high temperature was plotted against that observed at low temperature, neither the model for the same difference among cultivars in days, nor that in degree 

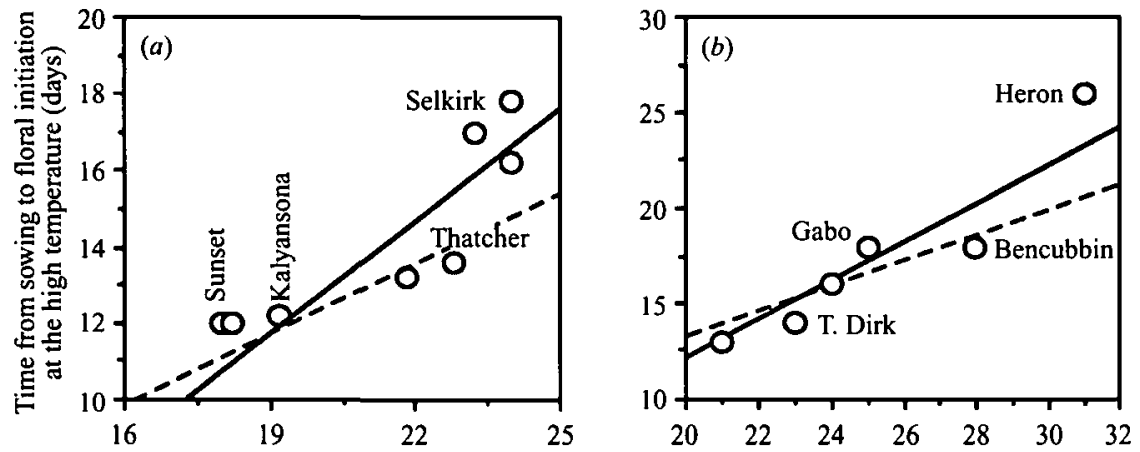

Time from sowing to floral initiation at the low temperature (days)
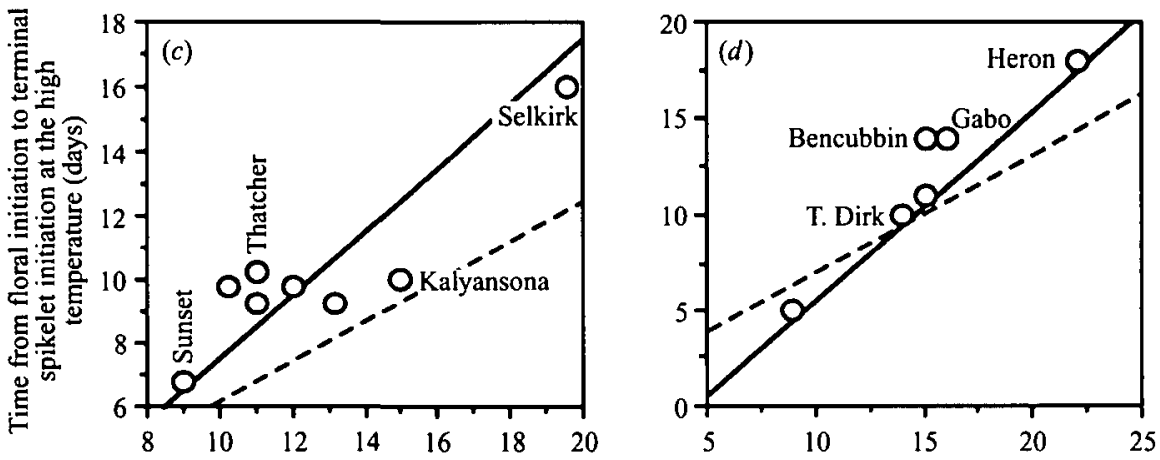

Time from floral initiation to terminal spikelet initiation at the low temperature (days)
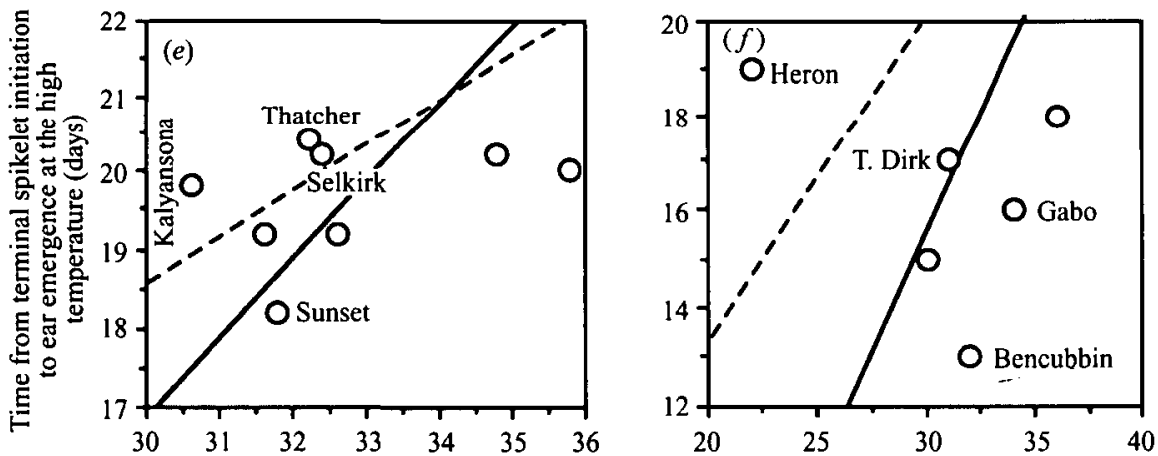

Time from terminal spikelet initiation to ear emergence at the low temperature (days)

Figure 9. Relationship between the duration of three different phenophases; $(a, b)$ from sowing to floral initiation, $(c, d)$ from floral initiation to terminal spikelet initiation and $(e, f)$ from terminal spikelet initiation to heading, at high temperature versus the duration of the same phenophases at low temperature, in the studies of $(a, c, e)$ Rahman \& Wilson (1978) and $(b, d, f)$ Rawson (1970). Lines represent the assumption that differences amongst cultivars remain constant in calendar time, using as intercept on the abscissa the average reduction of all cultivars in each study $(-)$, and in thermal time (-.-.) (see Fig. 3).

days, fitted the data well (Fig. $7 a, b$ ). Also the corresponding values from two additional studies (Wall \& Cartwright 1974; Pirasteh \& Welsh 1980) were not well fitted by either model (Fig. $7 c, d$ ), although they are not wholly suitable for the analysis as they did not include a photoperiod that was long enough to entirely remove responses to this factor. However, potentially the differences in response to 

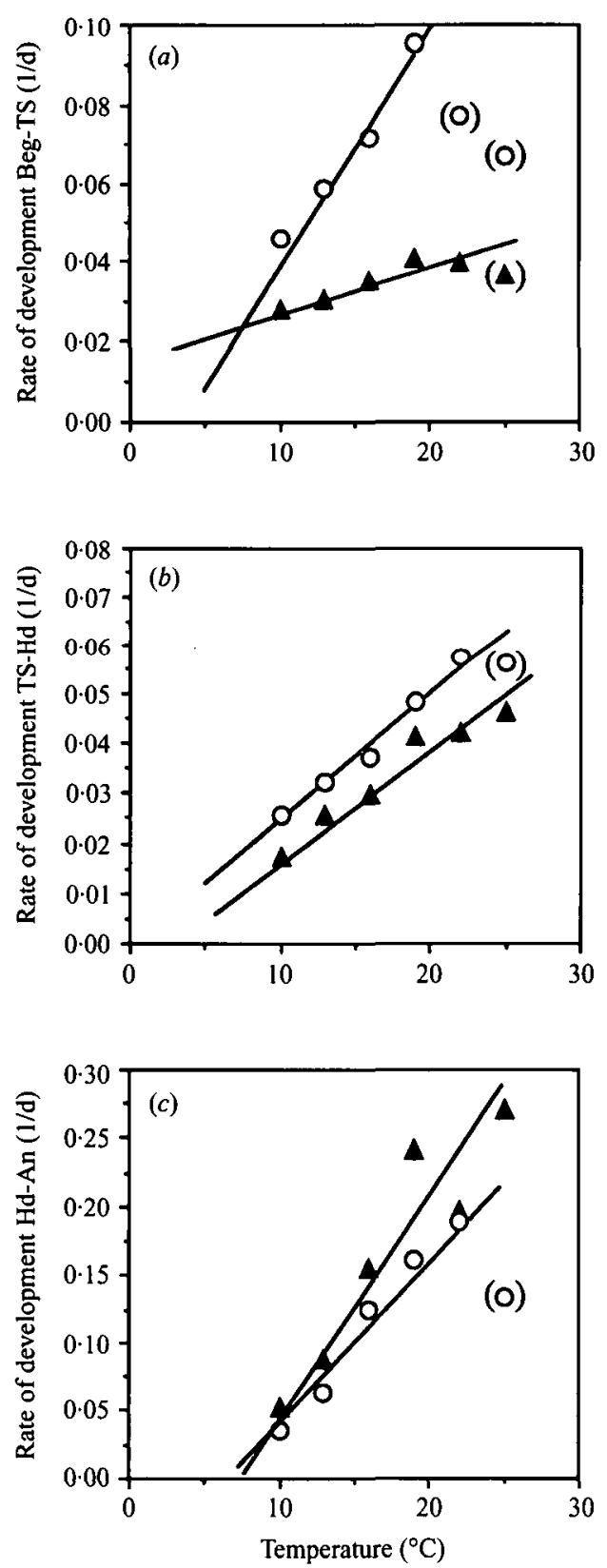

Figure 10. Relationships between rate of development during different phenophases and temperature. Phases were $(a)$ from the beginning of the experiment to terminal spikelet initiation, $(b)$ from terminal spikelet initiation to heading, and $(c)$ from heading to anthesis for cultivars Sunset $(O)$ and Cappelle Desprez $(\boldsymbol{\Delta})$ grown in sunlit cabinets under long photoperiod $(18 \mathrm{~h})$ and after being vernalized for 50 days at six constant temperatures ranging from 10 to $25^{\circ} \mathrm{C}$ (Slafer \& Rawson 1995a). The lines were fitted by linear regression. Data between brackets were removed from the analysis as they were considered to be above the optimum temperature. photoperiod should be amplifying the differences amongst cultivars at any thermal regime, but their relative or absolute differences should still remain constant. This was clearly not so (Fig. $7 c, d$ ). Changing the slope of the model of constant differences in thermal time by using a base temperature differing from $0^{\circ} \mathrm{C}$ for all cultivars did not improve the fit in any of the studies.

Slafer \& Rawson (1995a) conducted an experiment with four wheat cultivars grown after 50 days of vernalization at a daylength of $18 \mathrm{~h}$ under six different temperatures $\left(10-25^{\circ} \mathrm{C}\right)$. Data from that study can be used to test the relationships between the rate of development towards anthesis and temperature, and to determine whether cultivars differ in the parameters of the relationship. Only the response of the two extreme cultivars is shown in Fig. 8, where it is clear that sensitivity to temperature was not the same for both. Averaging across temperature regimes, Sunset was 18 days earlier than Cappelle Desprez, but their differences were strongly affected by temperature both in days and in degree days (Slafer \& Rawson $1995 b$ ). Although there were no actual changes in cultivar rankings within the range of temperatures used, the theoretical basis for expecting those changes is satisfied (i.e. Sunset possessed a higher base temperature and a lower thermal time than Cappelle Desprez, Fig. 8). To analyse the relationships in Fig. 8 , the points corresponding to $25^{\circ} \mathrm{C}$ were judged to be clearly above the optimum temperature (that under which the rate of development is maximum) and were excluded from the analysis. Because of the lack of many points above the optimum temperature, a precise determination of the optimum temperature and then an accurate selection of the points not to be included in the analysis is not possible. However, if an additional point for each cultivar (corresponding to $22^{\circ} \mathrm{C}$ ) is also removed from the analysis, the same conclusion is reached.

\section{Differences amongst different sub-phases}

Although the duration of the period from sowing to heading is the most common measure for assessing intrinsic earliness (Table 1), it is useful to assess to what degree intrinsic earliness might be associated with all sub-phases of development leading up to heading. Rawson (1970) and Rahman \& Wilson (1978) used three sub-phases from sowing to floral initiation, from floral initiation to terminal spikelet initiation, and from terminal spikelet initiation to ear emergence. Consequently, their data can be used to test the models described above for constant differences in days or degree days for each independent sub-phase.

Once again, all sub-phases for all the cultivars were shorter at high than at low temperatures, but neither model adequately matched the duration of all phases of development (Fig. 9). Some cultivars had a similar 

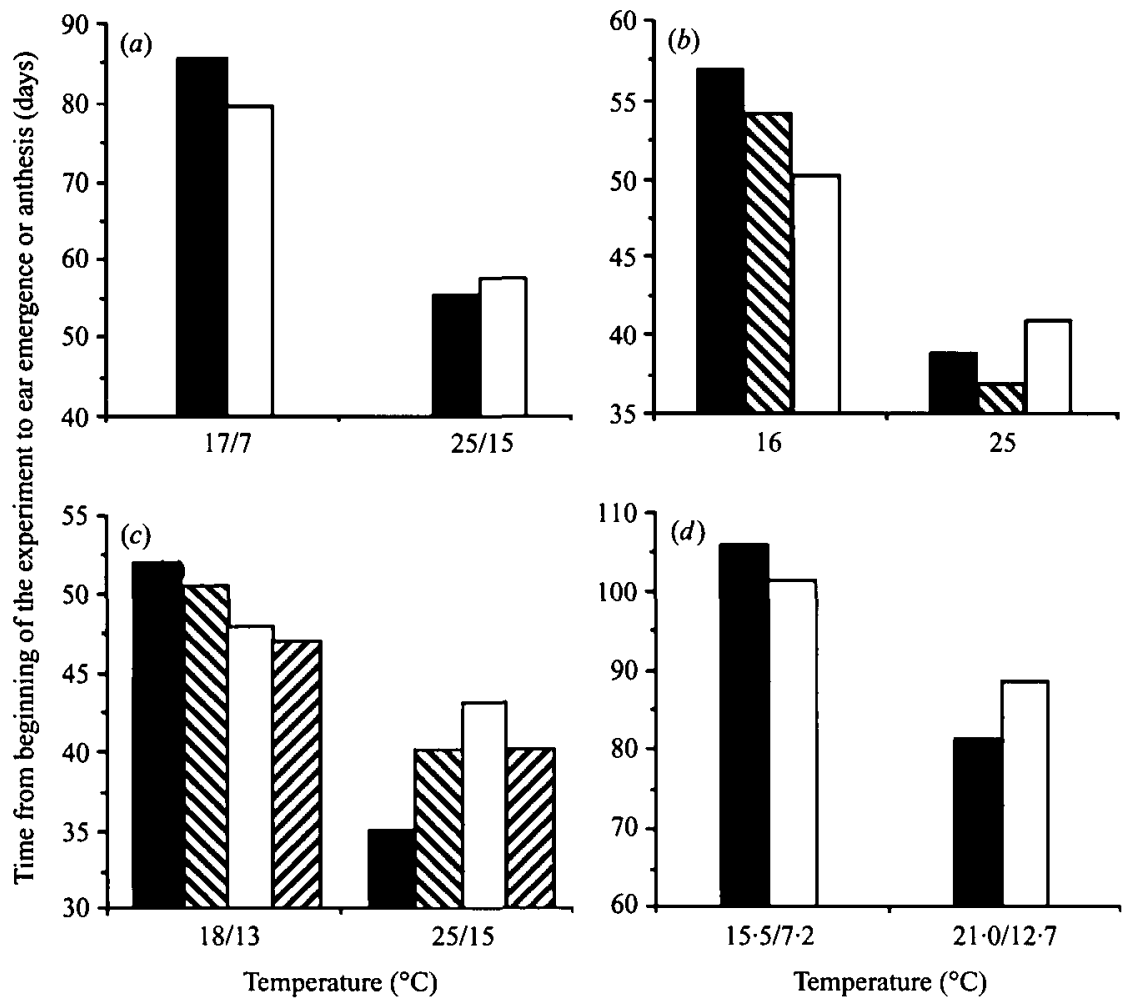

Figure 11. Time from beginning of the experiment to ear emergence or anthesis of different cultivars of wheat grown under two temperatures in the studies of $(a)$ Rawson \& Zajac (1993) with cultivars Hartog ( $\square$ ) and Late Hartog ( $\square$ ), (b) Slafer \& Rawson (1995a) with cultivars Sunset ( $\square$ ), Condor (\$) and Rosella ( $\square$ ), (c) Wall \& Cartwright (1974) with cultivars Odzi

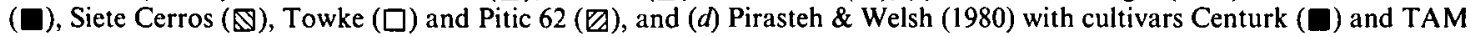
$101(\square)$. Not all cultivars from each study are shown.

sensitivity to temperature, but examples of genotypic variation in sensitivity were evident in both studies and in every sub-phase (Fig. 9). For example, if the duration of each sub-phase is compared in Gabo and Selkirk (Fig. $9 a, c, e$ ) and in Gabo and Bencubbin Fig. $9 b, d, f)$ in the studies carried out by Rahman \& Wilson (1978) and Rawson (1970), respectively, it is clear that the difference between Gabo and the other cultivars was not constant across both temperatures (either in calendar or thermal time) in any of the subphases. In the vegetative phase, Gabo was only $2 \cdot 2$ days earlier than Selkirk at $16 / 9^{\circ} \mathrm{C}$ but 4.6 days earlier at $23 / 16^{\circ} \mathrm{C}$ (i.e. 25 and $85^{\circ} \mathrm{Cd}$ ), respectively (Fig. 9a). Gabo and Bencubbin had similar durations for the vegetative phase at $21 / 16^{\circ} \mathrm{C}$, but Gabo was earlier at $15 / 10^{\circ} \mathrm{C}$ (Fig. $9 b$ ).

In the experiment with Sunset and Cappelle Desprez, Slafer \& Rawson (1995a) also divided the full phase to anthesis into sub-phases. As in the data just discussed, the durations of all phases were significantly affected by temperature, but each phase had an independent response and the cultivars were differentially sensitive (Fig. 10). In all phases, these cultivars differed both in base temperature and in thermal time required to complete the sub-phase (Fig. $10)$.

It is clear from the discussion above that there is no support for the third assumption, since the differences between cultivars in both the full period to ear emergence or anthesis, and in each of the sub-phases, were not constant in days or degree days. In addition, evidence for genetic variation in sensitivity to temperature was shown using a range of temperatures, including those frequently found in both temperate and sub-tropical wheat growing areas. Certainly, it would be quite bold to attempt to predict a value of basic earliness for a genotype at one temperature from knowing its value at another, and knowing nothing about its response to temperature (Slafer \& Rawson 1995b).

\section{Some examples of changes in ranking at different temperatures}

The previous discussion has shown that there is no constant quantitative value of intrinsic earliness for a genotype measured either in days or degree days, but 


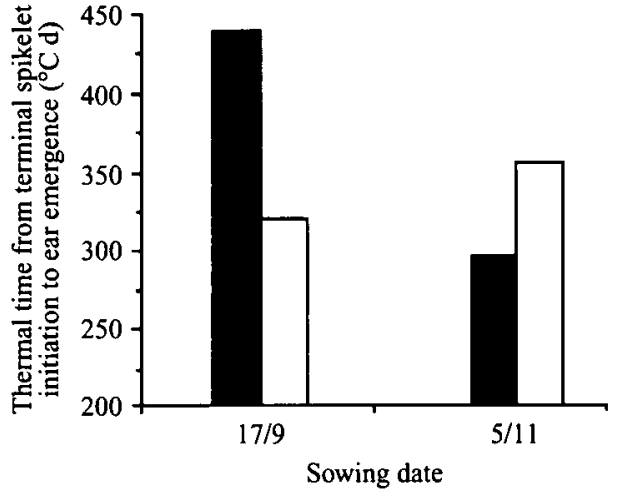

Figure 12. Thermal time from terminal spikelet initiation to ear emergence or anthesis for two cultivars of wheat, Falcon ( $\square$ ) and Pinnacle $(\square)$, grown in the field with differences in sowing date. In this experiment, photoperiod was artificially extended to $18 \mathrm{~h}$ (Flood \& Halloran 1984).

it is still possible that the concept may work qualitatively. In that event, the ranking of the cultivars for earliness should hold at any temperature.

There are some instances in the literature where the rankings of genotypes for intrinsic earliness did change with change in temperature. For example, Rawson \& Zajac (1993) grew Hartog and Late Hartog, at $17 / 7^{\circ} \mathrm{C}$ or $25 / 15^{\circ} \mathrm{C}$ under long days after 4 weeks of vernalization. While Hartog headed 2 days earlier than Late Hartog at the high temperature, their rankings were reversed at $17 / 7^{\circ} \mathrm{C}$ with Hartog being 6 days later than Late Hartog (Fig. 11 a). Obviously it is not possible to say which of these genotypes is intrinsically earlier than the other. Similarly, in Slafer \& Rawson (1995b), although there were no changes in rankings between the extreme genotypes, Cappelle Desprez and Sunset, there were some changes in rankings between Sunset and the other two cultivars used (Fig. $11 b$ ). Once again, the classification from intrinsically earlier to intrinsically later would be altered by temperature.

Data from Wall \& Cartwright (1974) and Pirasteh $\&$ Welsh (1980) provide a further example where the rankings of the cultivars for heading time were altered by temperature (Fig. $11 c, d$ ). They vernalized several cultivars and then grew them at a range of temperatures with common photoperiod regimes. Part of this response could have been due to a photoperiod $x$ temperature interaction as the photoperiods used did not satisfy the requirements of all cultivars.

These changes in rankings are also evident for different sub-phases. In the studies conducted by Rawson (1970) and Rahman \& Wilson (1978), changes could occur in any phase, but particularly in the stem elongation phase (Fig. 9). Any pair of data points that could be linked by a line parallel to one axis indicates that those cultivars were not different at one temperature (i.e. the same intrinsic earliness) but were different at the other temperature. Thatcher and Selkirk (Fig. 9a) and Gabo and Becubbin (Fig. 9b) are such examples for the vegetative period; while Thatcher and Sunset (Fig. 9e) and Triple Dirk and Bencubbin (Fig. 9f) are examples of cultivars with almost the same duration for the stem elongation phase at low temperature but quite different duration at high temperature. Other examples are shown in Fig. 9. More extreme cases are represented by any pair of data points that can be linked by a line with a negative slope, indicating that the cultivar that appeared to be intrinsically earlier at one temperature was apparently intrinsically later at the other temperature. The clearest, but not the only, examples of this cross-over are seen in the stem elongation phase when comparing Sunset and Kalyansona (Fig. 9e), and Bencubbin and Heron (Fig. $9 f$ ).

Flood \& Halloran (1984) grew two wheat cultivars at different sowing dates in the field and extended the photoperiod to $18 \mathrm{~h}$ with lamps installed over the crops. Using thermal units as a measure of time, Falcon had an 'intrinsically' shorter stem elongation phase than Pinnacle at the early (cooler) sowing date but the ranking was reversed in the later (warmer) sowing (Fig. 12). The fact that thermal time changed with sowing date in both cultivars, and particularly in Pinnacle, might indicate that the cultivars have very different base temperatures. Further examples of this cross-over can be found for the spikelet initiation phase in Halse \& Weir (1974).

All these examples show that even the ranking of cultivars for intrinsic earliness can change. Therefore, it seems that basic development rate and intrinsic earliness are convenient concepts that fail to allow for differential sensitivities to temperature amongst genotypes (Slafer \& Rawson 1995b).

\section{DISCUSSION}

Is there any point in putting breeding effort into searching for 'intrinsic' earliness? There should be at least some doubts on how worthwhile it might be, especially now that it appears that the ranking of cultivars for 'intrinsic earliness' can be changed, because of differential sensitivity to temperature. However, considering the practical use of intrinsic earliness', these changes in ranking are more or less important depending on the context of the application. Whilst these reversals may be physiologically true, they must be put into an agronomic context to answer the question.

Firstly, changes in rankings do not occur between genotypes which have an extreme expression of intrinsic earliness or lateness and, secondly, for those genotypes which have similar rankings, quite large temperature changes are needed to alter the rankings. Therefore, if the breeding programme is conducted 
under environmental conditions which are similar to those where the released cultivars will be grown, sensitivity to temperature could be disregarded.

Although most breeding programmes are conducted primarily in a similar environment to that for which the cultivar is targeted, it is not uncommon to use off-season generations to accelerate the process. If selection for intrinsic earliness were attempted then, i.e. in summer with long photoperiods and warm temperatures, responses for intrinsic earliness at normal planting times could not be guaranteed. The same arguments would apply to the use of warm glasshouses for breeding programmes.

Similar inconveniences can appear with the introduction of cultivars from a different region to that in which it will be grown. Genotype rankings for 'intrinsic earliness' (or lateness) in cool climates would not necessarily hold in the warm wheat growing areas of the subtropics and vice-versa. Therefore, if cultivars are going to be imported from one of these areas to the other, it would be necessary to know the sensitivity to temperature of the genotypes, as well as their sensitivities to photoperiod and vernalization, before being confident of predicting developmental patterns.

Another implication of the results presented in the present study is related to the modelling of plant development. If a crop simulation model is built to predict growth and development of wheat cultivars in a narrow range of environments, it does not appear to be important to consider the differential sensitivity of cultivars to temperature. However, if the aim is to produce a generic model, then the disregarding of differential temperature responses could cause problems. This is particularly important when models built for cool regions are used in sub-tropical areas. Rawson (1993) has recently highlighted some inaccuracies resulting from the conventional use of thermal time when comparing cultivars under cool and warm temperatures.

Some models are used for prediction alone. Then, the methods used to reach the answer are unimportant if the answer is correct. However when models are used as a research or teaching tool, the accuracy of the assumptions used in the models becomes very important, independently of how well the model predicts the final step. These mechanistic models should include routines for the differential responses to temperature of different cultivars.

\section{CONCLUDING REMARKS}

The assumptions that have been tested in this paper required the use of data taken from several studies and the re-interpretation of those data in ways that were not intended by their authors. A cautionary note must be added to all the interpretations. The most important is that it was always accepted that the long photoperiods and vernalization pretreatments used by the authors were sufficient to saturate the responses of the genotypes. Sometimes this could have been incorrect. It is virtually impossible to be sure that all the requirements for these factors are completely satisfied by what is accepted as long photoperiod or long vernalization. However, these assumptions were also made in the studies carried out to identify and quantify 'intrinsic earliness', and thus the error (if any) in the evaluation of the assumptions involved in the concept of 'intrinsic earliness' would not have been different from that occurring in the determination of the trait.

The main task of this paper was to make explicit the assumptions behind the concept of intrinsic earliness or basic development rate, and then to examine them using independent data from the literature. Only one of the four assumptions unconditionally held, that the trait examined altered the duration of the developmental phase quite independently of any direct effects of photoperiod and vernalization on the duration of that phase. The consequence of this was that any value of intrinsic earliness (at a determined temperature) could be combined with any level of sensitivity to photoperiod and vernalization.

The second assumption was rejected, since the differences between cultivars in time to ear emergence in the absence of photoperiod and vernalization effects could be due to differences in the length of any sub-phase of development. The effects of the length of the vegetative period on intrinsic earliness were not paramount. A further complication was that because the sub-phases of development are differentially sensitive to temperature, both the absolute and relative allocation of time to the sub-phases could change when a genotype was grown in different regimes. However, this different relative allocation of time to the sub-phases could be used to select genotypes with the same basic period to heading, but different basic periods for each sub-phase. This could be an avenue for improving the balance between the generation of different source and sink organs for different environments.

The other two assumptions, which are the strongest determinants of the concept of intrinsic earliness, were also not supported. The general conclusion that has arisen is that there is genotypic variation available for sensitivity to temperature, and that even if this variation is not as important as that found for sensitivity to photoperiod and vernalization (see also Table 1 in Slafer \& Rawson (1994)), it can still have important implications for agriculture.

This conclusion must be further tested in studies including several temperatures. This is a particularly interesting area of cereal development to be explored since an improved understanding of genetic variation in sensitivity to temperature could be of much benefit 
for future breeding in a changing, and particularly warmer, global environment.

I am deeply indebted to H. M. Rawson (CSIRO, Canberra) who not only shared with me his viewpoint on this subject, but also provided some very useful suggestions and comments on the manuscript. I am also grateful to J. Masle (RSBS, ANU) for valuable discussion. The author was on leave from the Department of Plant Production, Faculty of Agronomy, University of Buenos Aires and gratefully acknowledges the support given by CONICET (Consejo Nacional de Investigaciones Cientificas y Tecnicas, Argentina) and The University of Melbourne.

\section{REFERENCES}

Aitken, Y. (1974). Flowering Time, Climate and Genotype. Melbourne: Melbourne University Press.

Angus, J. F., Mackenzie, D. H., Morton, R. \& Schafer, C.A $(1981 a)$. Phasic development in field crops. II. Thermal and photoperiodic responses of spring wheat. Field Crops Research 4, 269-283.

Angus, J. F., Cunningham, R. B., Moncur, M. W. \& MacKenzie, D.H. (1981 $b$ ). Phasic development in field crops. I. Thermal response in the seedling phase. Field Crops Research 3, 365-378.

Bauer, A., Garcia, R., Kanemasu, E. T., Blad, B. L., Hatfield, J. L., Major, D. J., Reginato, R. J. \& HuBbard, K. G. (1988). Effect of latitude on phenology of 'Colt' winter wheat. Agricultural and Forest Meteorology 44, 131-140.

Beavis, W. D., Grant, D., Albertson, M. \& Fincher, R. (1991). Quantitative trait loci for plant height in four maize populations and their associations with qualitative genetic loci. Theoretical and Applied Genetics 83, 141-145.

Boyd, W. J. R., Kaveeta, L., Potipibod, S. \& Rossnagel, B. (1991). Variation in basic vegetative period and minimum leaf numbers. In Proceedings of the Sixth International Barley Genetics Symposium (Ed L. Munck), pp. 6-8. Helsingborg: Munksgaard International Publishers.

Davidson, J. L., Christian, K. R., Jones, D. B. \& Bremner, P.M. (1985). Responses of wheat to vernalization and photoperiod. Australian Journal of Agricultural Research 36, 347-359.

Evans, L. T. \& Blundell, C. (1994). Some aspects of photoperiodism in wheat and its wild relatives. Australian Journal of Plant Physiology 21, 551-562.

FISCHER, R. A. (1984). Wheat. In Symposium on Potential Productivity of Field Crops Under Different Environments (Eds W. H. Smith \& S. J. Banta), pp. 129-153. Los Baños: IRRI.

Flood, R. G. \& Halloran, G. M. (1984). Basic development rate in spring wheat. Agronomy Journal 76, 260-264.

Flood, R. G. \& Halloran, G. M. (1986). Genetics and physiology of vernalization response in wheat. Advances in Agronomy 39, 87-125.

Ford, M. A., Austin, R. B., Angus, W. J. \& Sage, G. C.M. (1981). Relationships between the responses of spring wheat genotypes to temperature and photoperiodic treatments and their performance in the field. Journal of Agricultural Science, Cambridge 96, 623-634.

FRANK, A. B., BAUER, A. \& BlaCK, A. L.(1987). Effects of air temperature and water stress on apex development in spring wheat. Crop Science 27, 113-116.

GaLlaGHER, J. N. (1979). Field studies of cereal leaf growth. I. Initiation and expansion in relation to temperature and ontogeny. Journal of Experimental Botany 30, 625-636.
Halloran, G. M.(1977). Developmental basis of maturity differences in spring wheat. Agronomy Journal 69, 899-902.

Halloran, G. M. \& Pennell, A. L. (1982). Duration and rate of development phases in wheat in two environments. Annals of Botany 49, 115-121.

HALSE, N. J. \& WEIR, R. N. (1974). Effects of temperature on spikelet number of wheat. Australian Journal of Agricultural Research 25, 687-695.

HAY, R. K. M. (1986). Sowing date and the relationships between plant and apex development in winter cereals. Field Crops Research 14, 321-337.

HAY, R. K. M \& KIRBY, E. J.M. (1991). Convergence and synchrony - a review of the coordination of development in wheat. Australian Journal of Agricultural Research 42, 661-700.

HoOGENDOORN, J. (1985). The basis of variation in date of ear emergence under field conditions among the progeny of a cross between two winter wheat varieties. Journal of Agricultural Science, Cambridge 104, 493-500.

Johnson, I. R. \& ThORNLEY, J. H. M. (1985). Temperature dependence of plant and crop processes. Annals of Botany $55,1-24$.

Kato, K. \& Yamagata, H. (1988). Method for evaluation of chilling requirement and narrow-sense earliness of wheat cultivars. Japanese Journal of Breeding 38, 172-186.

KeIM, D. L., WelSH, J. R. \& McConnell, R. L. (1973). Inheritance of photoperiodic heading response in winter and spring cultivars of bread wheat. Canadian Journal of Plant Science 53, 247-250.

Kirby, E. J. M., Appleyard, M. \& Fellowes, G. (1985) Variation in development of wheat and barley in response to sowing date and variety. Journal of Agricultural Science, Cambridge 104, 383-396.

Kirby, E. J. M., Porter, J. R., Day, W., ADaM, J. S., Appleyard, M., Ayling, S., BaKer, C. K., Belford, R. K., Biscoe, P. V., Chapman, A., Fuller, M. P., Hampson, J., HaY, R. K. M., Matrhews, S., Thompson, W. J., Weir, A. H., WILlington, V. B. A. \& WoOD, D. W. (1987). An analysis of primordium initiation in Avalon winter wheat crops with different sowing dates and at nine sites in England and Scotland. Journal of Agricultural Science, Cambridge 109, 123-134.

Koester, R. P., Sisco, P. H. \& Stuber, C. W. (1993). Identification of quantitative trait loci controlling days to flowering and plant height in two near isogenic lines of maize. Crop Science 33, 1209-1216.

MaJor, D. J. (1980). Photoperiod response characteristics controlling flowering of nine crop species. Canadian Journal of Plant Science 60, 777-784.

MaJor, D. J. (1983). Determination of photoperiod response characteristics using a greenhouse. International Journal of Biometeorology 27, 117-124.

Manupeerapan, T., Davidson, J. L., Pearson, C. J. \& 
Christian, K. R. (1992). Differences in flowering responses of wheat to temperature and photoperiod. Australian Journal of Agricultural Research 43, 575-584.

Masle, J., Doussinault, G. \& Sun, B. (1989). Response of wheat genotypes to temperature and photoperiod in natural conditions. Crop Science 29, 712-721.

Miura, H. \& Worland, A. J. (1994). Genetic control of vernalization, day-length response, and earliness per se by homoeologous group-3 chromosomes in wheat. Plant Breeding 113, 160-169.

Monteith, J. L. (1977). Climate. In Ecophysiology of Tropical Crops (Eds P. de T. Alvim \& T. T. Kozlowski), pp. 1-27. New York: Academic Press.

Morrison, M. J., McVetty, P. B. E. \& Shaykewich, C. F. (1989). The determination and verification of a baseline temperature for the growth of Westar summer rape. Canadian Journal of Plant Science 69, 455-464.

Penrose, L. D. J., Martin, R. H. \& Landers, C. F. (1991). Measurement of response to vernalization in Australian wheats with winter habit. Euphytica 57, 9-17.

Pirasteh, B. \& Welsh, J. R. (1980). Effect of temperature on the heading date of wheat cultivars under a lengthening photoperiod. Crop Science 20, 453-456.

PORTER, J. R. \& Delécolle, R. (1988). Interaction of temperature with other environmental factors in controlling the development of plants. In Plants and Temperature (Eds S. P. Long \& F. I. Woodward), pp. 133-156. Cambridge: The Company of Biologists Limited.

RaHman, M. S. (1980). Effect of photoperiod and vernalization on the rate of development and spikelet number per ear in 30 varieties of wheat. Journal of the Australian Institute of Agricultural Science 46, 68-70

RaHman, M. S. \& WILSON, J. H. (1977). Determination of spikelet number in wheat. I. Effect of varying photoperiod on ear development. Australian Journal of Agricultural Research 28, 565-574.

RAHMAN, M. S. \& WILSON, J. H. (1978). Determination of spikelet number in wheat. III. Effect of varying temperature on ear development. Australian Journal of Agricultural Research 29, 459-467.

Rawson, H. M. (1970). Spikelet number, its control and relation to yield per ear in wheat. Australian Journal of Biological Sciences 23, 1-5.

Rawson, H. M. (1993). Prediction of heading time in wheat grown under high temperatures: effects of temperature, vernalisation and photoperiod. Indian Journal of Plant Physiology 36, 243-249.

RAWSON, H. M. \& ZAJAC, M. (1993). Effects of higher temperatures, photoperiod and seed vernalisation on development in two spring wheats. Australian Journal of Plant Physiology 20, 211-222.

SAviN, R. (1993). Profundidad de enraizamiento, siembra temprana y sus efectos sobre el rendimiento de trigo sometido a sequias inverno-primaverales: Analisis de estrategias de manejo con un modelo de simulacion. MSc thesis, University of Buenos Aires.
Slafer, G. A. \& Rawson, H. M. (1994). Sensitivity of wheat phasic development to major environmental factors: a reexamination of some assumptions made by physiologists and modellers. Australian Journal of Plant Physiology 21, 393-426.

Slafer, G. A. \& Rawson, H. M. (1995a). Base and optimum temperatures vary with genotype and stage of development in wheat. Plant Cell \& Environment 18, 671-679.

Slafer, G. A. \& Rawson, H. M. (1995b). Intrinsic earliness and basic development rate assessed for their response to temperature in wheat genotypes. Euphytica 83, 175-183.

Slafer, G. A. \& Savin, R. (1991). Developmental base temperature in different phenological phases of wheat (Triticum aestivum). Journal of Experimental Botany 42, $1077-1082$.

Slafer, G. A., Halloran, G. M. \& Connor, D. J. (1994). Development rate in wheat as affected by duration and rate of change of photoperiod. Annals of Botany 73, 671-677

SymE, J. R. (1968). Ear emergence of Australian, Mexican and European wheats in relation to time of sowing and their response to vernalization and daylength. Australian Journal of Experimental Agriculture and Animal Husbandry 8, 578-581.

TAKahashi, R. \& YASUdA, S. (1971). Genetics of earliness and growth habit in barley. In Proceedings of the Second International Barley Genetics Symposium (Ed R. A. Nilan) pp. 388-408. Wageningen: Centre for Agricultural Publications and Documentation.

Vergara, B. S. \& Chang, T. T. (1976). The flowering response of the rice plant to photoperiod. A review of the literature. International Rice Research Institute, Technical Bulletin 8.

VONGBURI, K. (1992). Studies on developmental variation in wheat in relation to adaptation to the tropical environments. PhD thesis, The University of Western Australia.

WALl, P. C. \& Cartwright, P. M. (1974). Effects of photoperiod, temperature and vernalization on the phenology and spikelet numbers of spring wheats. Annals of Applied Biology 76, 299-309.

Wallace, D. H. (1985). Physiological genetics of plant maturity, adaptation, and yield. Plant Breeding Reviews 3, 21-167.

Worland, A. J., A ppendino, M. L. \& SAyers, E. J. (1994). The distribution, in European winter wheats, of genes that influence ecoclimatic adaptability whilst determining photoperiodic insensitivity and plant height. Euphytica 80, 219-228.

YASUDA, S. (1981). The physiology of earliness in barley. In Proceedings of the Fourth International Barley Genetics Symposium, pp. 507-517. Edinburgh, UK.

Young, K. J. \& ElliotT, G. A. (1994). An evaluation of barley accessions for adaptation to the central growing regions of Western Australia, based on time to ear emergence. Australian Journal of Agricultural Research 45, $75-92$. 